\title{
DEMOGRAPHIC DEBATE
}

\section{What should be the goal of population policies? Focus on 'Balanced Human Capital Development'}

\author{
Wolfgang Lutz*
}

Many governments in Europe report in international enquiries that they are dissatisfied with the current demographic trends in their countries. The further one goes to the east of the continent, the stronger the publicly expressed concern. While the prime minister of Bulgaria calls his country's 'demographic crisis' the number one policy priority, the president of Belarus even speaks of a national 'demographic security crisis', implying that this may require equally drastic action as a security crisis at the military level. Less dramatic in tone but equally urgent in its message, the President of the European Commission repeatedly called Europe's demographic trends one of the three main challenges facing Europe, the other two being globalisation and technological change.

What do these policy makers have in mind when they refer to demographic crises or challenges? In the eastern part of Europe, where most countries (with the notable exception of Russia, which received many Russians from other former Soviet republics) have experienced significant population declines since the political transformation around 1990 , the concern seems to be very deeply rooted and associated with the fear that the country will lose its population base. Bulgaria, for example, had close to 9 million inhabitants in the late 1980s; now (2008) it has only 7.6 million and is projected by Eurostat (2008) to further shrink to around 6.5 million in 2035 and 5.5 million in 2060. This loss of more than onethird of its entire population, which is also associated with very rapid population ageing, is indeed significant, particularly in the context of traditional thinking, where more population meant more soldiers and more power, but also in view of the fact that throughout human history, population shrinking has always been associated with misery and national decline. In western Europe the story is less

* Wolfgang Lutz, World Population Program, International Institute for Applied Systems Analysis (IIASA), Schlossplatz 1, 2361 Laxenburg, Austria and Vienna Institute of Demography, Austrian Academy of Sciences, Vienna, Austria. Email: lutz@oeaw.ac.at 
dramatic because thanks to migration gains, only very few countries are already on a declining trajectory and the public policy concern is mostly with respect to the implications of population ageing.

What should be the goal of government policies in this context? In a similar commentary published in the 2007 Vienna Yearbook of Population Research (Lutz 2007) I had argued that - in analogy to the climate policy discussiongovernments will have to choose whether they only want to focus on adaptation (taking the demographic trends as given and trying to adjust as well as possible to their inevitable consequences) or whether they want to decide on a mitigation strategy in which they attempt to influence the demographic trends themselves. Usually in the West, governments refer mostly to adaptation policies whereas in the East, mitigation and in particular attempts to directly influence the birth rates figure prominently. Generally speaking, of the three forces of demographic change (fertility, mortality and migration), fertility lends itself best to mitigation policies. As for mortality, the goal is in all cases set into the direction of further decline which (except for child and young adult mortality) will essentially result in stronger and more rapid population ageing. Hence it is not a viable policy variable for reducing the speed of ageing. Migration is certainly a very important policy variable in this context but it could be viewed as either an adaptation or a mitigation strategy because it can vary at short notice: Once a real labour shortage, as a consequence of changing age structure, becomes manifest, more immigrants can be brought into the country, and hence this can be seen as a way to adapt to this shortage. Only fertility is an important long-term mitigation policy variable, where alternative birth rates in the near future will have a great impact on the longer-term demographic structure.

There is also an interesting dynamic element in the timing of possible policies affecting fertility that may have great impact but has so far received little attention. Particularly in the context of the Low Fertility Trap Hypothesis (LFTH) paradigm - which assumes a self-reinforcing process in which low fertility leads to lower ideal family size which in turn will lead to even lower fertility-it may make all the difference for long-run trends whether policies aimed at increasing fertility are implemented in the very near term or in the more distant future, where desired family size may already have declined as a consequence of extended periods of very low fertility (see Lutz et al. 2006). Since the LFTH assumes a feedback loop from low actual fertility and the fact that there are few children around during the time when the next generation is being socialised to a declining desired family size of this very generation, the timing of policies becomes crucial in such a dynamic framework. Since fertility-enhancing policies are mostly aimed at trying to close the presumed gap between (higher) desired family size and (lower) actual fertility, the LFTH framework implies an urgency of such measures in order to bring actual fertility up to a higher level at a point in time when desired fertility has not yet declined irreversibly. Once values have changed in such a way that large segments of the younger population no longer consider children as an 
important element of a successful life, there will be precious little that policies can do to increase the birth rate. Hence, if the LFTH is right, the timing of such policies is crucial. If it is wrong and people will always want around two children on average, the whole matter has little urgency. Hence, as a matter of urgency, we need more research evaluating the LFTH.

If fertility is seen as the key policy variable in a mitigation context, what level of fertility should then be seen as 'optimal', as the target and goal of such policies? Most demographers would probably intuitively refer to replacement level fertility (two surviving children per woman) as such a target. But why should that be the case? Wouldn't a moderate decline in cohort size that is associated with better education of those fewer children be preferable by many criteria that range from per capita welfare to environmental sustainability?

\section{From population stabilisation to balanced human capital development}

In the remaining part of this short commentary, I want to go beyond the traditionally rather narrow demographic focus on population size and age structure and focus more broadly on human capital as a possible goal of public population-related policies. In doing so I want to refer to some work we did at IIASA (Lutz et al. 2004) in terms of defining a simple quantitative model of what we then called 'population balance' in an attempt to explain by a joint model why both too high and too low fertility levels are considered undesirable. I will also refer to some interaction I recently had with the government of Bulgaria, where the concept of balanced population and human capital actually became enshrined in the official national population policy. Since our original notion of 'population balance' has recently been used by a rather vocal American NGO (http://worldpopulationbalance.org/) with a very specific agenda, I now choose to use the notion of 'balanced human capital' instead, meaning the same thing.

In the global-level policy debate, for decades the notion of 'population stabilisation' has been the guiding principle and the explicit goal of virtually all population-related policies, both within the United Nations (UN) system and outside. The international political goal of population stabilisation corresponds nicely to the UN population projections which used to assume that in the longer run, all countries of the world converge in their fertility rates to replacement level, resulting (in combination with an assumed levelling-off of life expectancy) in a long-term stabilisation, i.e. constant size of the world population as well as of the population of all individual countries. Such a perceived future of population stabilisation is likely to please government officials who do not want to see their population as either disappearing or exploding in the long run. The only problem with this politically attractive concept is that the real world does not seem to follow it. A majority of the world's population already has fertility below replacement level and there is little reason to assume that all countries would eventually converge to this level (Lutz et al. 2006). Actually the most recent probabilistic population projections by IIASA (Lutz et al. 2008) indicate a 
probability of more than 85 per cent that world population will peak during this century and then start to decline; this is very different from stabilisation. The notion becomes even more problematic at the level of individual countries. What does the goal of population stabilisation imply for Bulgaria? Does it call on the government to bring the population back up to the 9 million mark of the late 1980 s, or keep it constant at the current 7.6 million, or stop it from declining below 7.0 million? None of these seem to be a realistic goal for Bulgaria. But what would be an appropriate population-related goal for Bulgaria? Since this is not obvious, I see a great need for coming up with a more useful and more comprehensive policy paradigm and goal that includes education as well as the number of people by age and sex.

The message I tried to convey to the government of Bulgaria in its process of defining a national population policy was the following: People are the wealth of nations. But it is not only the number of people that counts, it is also the skills, abilities and health status of the people that matter. All these aspects viewed together can be called the human resources base, or human capital in more economic language. This broadened view of population also implies that political goals should not be defined in terms of population size but rather in terms of human resources available for producing the best possible quality of life for all citizens.

This shift in paradigm, from a focus on only population size to one that aims at a balanced development of the population by age and sex as well as their capabilities and skills, is not an easy one because for centuries, population size has been the primary target of national and international population policies. Throughout European history, one view has dominated: it assumed that the bigger a kingdom/republic in terms of population, the more powerful this state would be and the better it would be for all of the citizens (Coleman 2006). The rationale behind this view has been primarily in military terms: the bigger the population, the more potential soldiers and the greater the possibilities to defend, or expand, the national territory. But there has been economic reasoning behind this view as well: more people imply greater markets with more trade, and higher population density furthers the division of labour and technological progress - all things that are considered to be conducive for economic growth. In the specific case of Bulgaria, the accession to the European Union brought a huge increase in the market even under conditions of population decline.

The opposite view that population growth is detrimental to human wellbeing also has a long tradition (at least since Robert Malthus). Here the reasoning has been that the resource base is limited for any national population and that population growth which leads to higher population density may in the end surpass the carrying capacity of a given territory and hence would lead to lower quality of life and even starvation and death. With such reasoning, regions such as the Netherlands or England were labelled overpopulated in the 19th century. But in reality through colonisation and international trade, the resource base of these 
countries could be expanded and technological progress has resulted in a much higher quality of life combined with higher population density. A modern version of this Malthusian view is reflected in the "Limits to Growth" study by the Club of Rome (Meadows et al. 1972) and more recently in the notion of the "ecological footprint' that shows how the number of people in a country and their consumption have ecological consequences far beyond the territory of a given country. There also have been many discussions of what the 'optimal' population size of a given country would be. While this discussion has been inconclusive, the majority of researchers in the field have understood that it makes little sense to have this one-dimensional focus on absolute population size. What really matters is the change over time and most importantly the composition of the population.

Demographers tend to study the composition of the population mostly with respect to age and sex. Changes in the age structure of a population matter for society and the economy in many respects. Most importantly, it is the ratio of persons who pay into the social security system to those who withdraw from it. More generally, it is the number of people who primarily produce compared to those who primarily consume. Significant changes in this ratio can be associated with decreases in the wellbeing of the population. In terms of pension systems, the expectation is that as the population age structure is bound to become much older, with the proportion of the population above age 60 increasing rapidly, there will be growing pressure toward one of the following measures: increasing the mean age of retirement, or decreasing the pension benefits, or increasing the individual contributions to the system, with the alternative of having a huge deficit in the pension fund. Most European countries typically show a combination of these responses. But the process of population ageing has only started. Significant future ageing is already pre-programmed in the existing population age structure, most importantly as a consequence of very low fertility over the last decade. Bulgaria has some more time to prepare for the peak of population ageing than most other European countries, where fertility already declined steeply during the 1970s, a period during which Bulgaria still had fertility rates around replacement level.

There is little doubt that population ageing will pose many serious challenges to European societies and that the more rapidly the proportion of elderly increases in a population, the greater the challenge will be. In this sense-at least at the national level-population ageing is clearly more relevant than decline in absolute population size in terms of potentially diminishing the welfare of individuals. Therefore, should it be the goal of a population policy to try to minimise the speed of population ageing? It would clearly be a more meaningful goal than trying to attain a certain absolute population size because it is much more directly related to consequences for the wellbeing of the population. But this is not yet the full story. Whether a smaller number of young workers actually translates into a decline in total production depends not only on the number of workers but also on the productivity of these workers. If productivity per worker 
increased at the same rate as the number of workers declined, it would not make any difference for total production (although a distributional issue still remains). There are many factors that contribute to the growth of productivity, but the most important seems to be human capital, a consequence primarily of the education of workers and to some extent of their health status and motivation. In other words, the future development in human capital formation is a crucial determinant of the question to what extent population ageing and decline have negative consequences for the wellbeing of the population. But again, it greatly depends on the skills and capabilities of the additional people whether they are to the benefit or detriment of society.

This focus on human capital is not new in the history of demographic thinking. In 1958 Alfred Sauvy wrote in the context of the miracle of Germany's economic rise after total destruction in 1945 and the fact that it had to absorb five million refugees: "Why this success, contrary to the forecasts of all doctrines ...? Because these men without capital came with their knowledge, their qualifications. They worked and they recreated the capital that was lacking, because they included a sufficient number of engineers, mechanics, chemists, doctors, sociologists, etc. If five million manual workers had entered Western Germany instead there would be five million unemployed today." (Sauvy 1958, cited from English translation 1963, p. 169). Despite the demographic prominence of Sauvy, mainstream demography has not really incorporated this important line of thinking. Instead such 'quality dimensions' were considered too difficult to measure and largely left to economists. Only the more advanced demographic tools of multi-state population dynamics, pioneered at and around IIASA in the 1970s now allows us to fully and quantitatively integrate the educational attainment dimension into formal demography. As the title of an article by Lutz et al. (1998) "Adding Education to Age and Sex" says, it seems to be time to more systematically apply the human capital approach in standard population analysis and consequently in population policy.

Today, in most countries, the fact that young people are on average better educated than older people - a consequence of educational improvements over several decades - is in itself a reason for optimism because it tells us that further improvements in human capital are already pre-programmed into the current age structure. Over time the less educated, older workers will retire and will be replaced by younger, better educated workers. This also illustrates that the educational composition of the labour force changes only very slowly and that possible efforts for better education over the coming years would only further improve the human capital of the younger workers in the near future. Under conditions of rapidly changing technologies, however, such additional education will be particularly important.

The concept of 'human capital balance' combines the concerns about population size with the concerns about the age structure and that of human capital. It goes beyond the more traditional population policy paradigm of 
'population stabilisation' which has a one-dimensional focus on population size. Population stabilisation is not a viable policy goal for Bulgaria and for many other countries in Europe over the coming decades because further population shrinking and ageing are already pre-programmed in the given age distribution. Even in the unlikely case that fertility rates increased again up to replacement level, the small cohorts of women born over the past one and a half decades indicate fewer potential mothers in the future and therefore fewer numbers of babies born. Population balance as a policy paradigm also considers human capital and its distribution by age and sex. This does not imply that the three determinants of population size and age structure-fertility, mortality and migration-do not matter. They continue to be the key drivers of change but they also must be seen in their interactions with education. In the case of migration, for instance, under a human capital perspective, it would not only be the numbers of migrants that count but the numbers (by age and sex) times their skills and qualifications. There are also important interactions between education and fertility (with higher educated women having their births later but also having on average better educated children) and mortality (more educated people being in general more healthy) that need to be considered in the formulation of policies.

How would this general concept translate into specific policies that would move a country like Bulgaria toward a better human capital balance? There is no easy and quick answer because we are dealing with a multi-dimensional phenomenon with different priorities under different conditions. It may be helpful to look at the definition of the word 'balance' in a dictionary. It says that in the field of music 'balance' refers to 'relative volume of different sources of sound' or, more inspiring, in art it means 'the harmony of proportions'. Further scientific research (including alternative projections) as well as a dialogue among stakeholder groups, civil society and government is necessary to find out what is the best harmony of the proportions of people of different ages and different levels of education that will form the future society. Specific policies can then be defined against the background of a shared view of what is a desirable and what is an achievable balance of different age and education groups in society.

\section{References}

Coleman, D. 2006. "Europe's demographic future: Determinants, dimensions and challenges.” In: P. Demeny and G. McNicoll (eds.) The political economy of global population change, 1950-2050, supplement to Population and Development Review 32: 52-95.

Lutz, W. 2007. "Adaptation versus mitigation policies on demographic change in Europe." Vienna Yearbook of Population Research 2007: 19-25.

Lutz, W., A. Goujon, and G. Doblhammer-Reiter. 1998. "Demographic dimensions of forecasting: Adding education to age and sex." In: W. Lutz, J. W. Vaupel, and D. 
Ahlburg (eds.) Frontiers of Population Forecasting, supplement to Population and Development Review 24: 42-57.

Lutz, W., W. C. Sanderson and B. C. O’Neill. 2004. "Conceptualizing population in sustainable development: From 'population stabilization' to 'population balance'." In: W. Lutz, W. C. Sanderson, and S. Scherbov (eds.) The End of World Population Growth in the $21^{\text {st }}$ Century: New Challenges for Human Capital Formation and Sustainable Development. London, Earthscan, pp. 315-334.

Lutz, W., W. C. Sanderson, and S. Scherbov. 2008. "The coming acceleration of global population ageing." Nature 451: 716-719.

Lutz, W., V. Skirbekk, and M. R. Testa. 2006. "The low fertility trap hypothesis: Forces that may lead to further postponement and fewer births in Europe." Vienna Yearbook of Population Research 2006: 167-192.

Meadows, D. H., D. L. Meadows, J. Randers, and W. W. Behrens III. 1972. The Limits to Growth. New York, Universe Books.

Sauvy, A. 1963. Fertility and Survival: Population Problems from Malthus to Mao Tsetung. New York, Collier Books. (Original version, De Malthus à Mao-Tsé-Tung, published in 1958, Paris, Denoel). 